\title{
PERCEPÇÃO ESPACIAL ESTUDANTIL DE PÁTIOS EM ESCOLAS PÚBLICAS DE ENSINO FUNDAMENTAL EM PALMITINHO, RS, BRASIL
}

\section{STUDENTS PERCEPTION OF SCHOOL YARD SPACE IN PUBLIC PRIMARY SCHOOLS IN PALMITINHO, RS, BRAZIL}

\author{
Gracielle Rodrigues da Fonseca Rech ${ }^{1}$ \\ Universidade Federal de Santa Catarina, Florianópolis, SC, Brasil, graciellerfrech@ hotmail.com \\ Ângela do Valle ${ }^{2}$ \\ Universidade Federal de Santa Catarina, Florianópolis, SC, Brasil, angela.valle@ufsc.br
}

Bruna Cristina Lermen ${ }^{3}$

Universidade Regional Integrada do Alto Uruguai e das Missões, Frederico Westphalen, RS, Brasil, brunalermen@hotmail.com.

\section{Resumo}

Em arquitetura, o processo de apropriação espacial é facilitado por espaços qualificados para os usuários, com aspectos ambientais que proporcionam bem-estar. Partindo do tema arquitetura de pátios escolares, a pesquisa teve por objetivo analisar o pátio de escolas públicas de ensino fundamental, segundo o ponto de vista do estudante. O enfoque foi dado ao pátio escolar, enquanto ambiente de lazer e aprendizado. Investigou-se e caracterizou-se a qualidade das áreas livres e do ambiente construído, com o propósito de analisar as relações de uso e apropriação desses espaços. Com base no reconhecimento da importância do pátio escolar como uma recorrência referencial na percepção dos usuários, é possível considerar o pátio escolar como um lugar de socialização, de troca e de convívio, bem como de exploração e de experimentação. Realizou-se uma revisão de literatura para elencar os possíveis elementos capazes de facilitar a apropriação nos pátios escolares por parte dos alunos. O artigo apresenta a avaliação realizada em duas instituições públicas de ensino fundamental localizadas no município de Palmitinho - Rio Grande do Sul, com ênfase nos instrumentos de análise aplicados: mapa cognitivo, poema dos desejos e mapa comportamental. A participação dos usuários mostrou-se fundamental para a obtenção de espaços de qualidade.

Palavras-chave: Pátio escolar. Percepção espacial. Psicologia ambiental.

\begin{abstract}
In architecture, the spatial appropriation process may be facilitated by spaces qualified for users, with environmental aspects that provide well-being. The research, in the theme of schoolyard architecture, aimed to analyze the courtyard of public elementary schools, according to the student's point of view. The focus was given to the schoolyard as a leisure and learning environment. We investigated and characterized the quality of free areas and the built environment, analyzing the relations of use and appropriation of these spaces. Based on the recognition of the importance of the schoolyard as a referential recurrence in the perception of users, it is possible to consider the schoolyard as a place of socialization, exchange, and acquaintanceship, as well as exploration and experimentation. The developed literature review indicated the possible elements capable of facilitating the appropriation of the schoolyards by students. The article presents the evaluation carried out in two public institutions of primary education located in the municipality of Palmitinho - Rio Grande do Sul, with emphasis on applied analysis tools: cognitive map and poem of desires. The participation of users determined to be fundamental for space quality acquisition.
\end{abstract}

Keywords: Schoolyard. Spatial perception. Environmental psychology.

How to cite this article:

RECH, Gracielle Rodrigues da Fonseca; VALLE, Ângela do; LERMEN, Bruna Cristina. Percepção espacial estudantil de pátios em escolas públicas de ensino fundamental em Palmitinho, RS, Brasil. PARC Pesquisa em Arquitetura e Construção, Campinas, SP, v. 9, n. 1, p. 57-68, mar. 2018. ISSN 1980-6809. Disponível em: <https://periodicos.sbu.unicamp.br/ojs/index.php/parc/article/view/8649936>. Acesso em: 03 fev. 2018. doi:http://dx.doi.org/10.20396/parc.v9i1.8649936. 


\section{Introdução}

A educação de uma criança se inicia no convívio familiar sendo, posteriormente, dividida com a escola que participa cada vez mais precocemente do processo educacional.

Neste contexto, o pátio escolar constitui um ambiente fundamental para o desenvolvimento e socialização das crianças, ao permitir interação entre elas e todos que fazem parte das escolas (NORBERG-SCHULZ; DIGERUD, 1981).

Do ponto de vista da Arquitetura, um bom espaço físico escolar, expressado pelos aspectos perceptivos conceituais, formais e estéticos - é aquele reconhecido pela representatividade e que influência o seu entorno próximo, afirma Kowaltowski (2011).

A harmonia entre o usuário e o ambiente é uma questão que deve ser evidenciada, pois deve haver uma interação entre espaço físico, atividades pedagógicas e comportamento humano. Assim, o enfoque no estudo do pátio escolar pode ser justificado pelo mesmo configurarse como elemento importante na formação do ser humano.

Embora, o pátio escolar exerça uma importante função, que influencia todo o processo de desenvolvimento infantil, há poucas reflexões sobre a concepção de pátios escolares no Brasil. É comum, durante o processo projetual, que a área destinada ao pátio seja tratada como um "espaço residual - 'sobra' do terreno -, inadequado para as atividades de recreação, exploração, convívio e socialização das crianças" (AZEVEDO; RHEINGANTZ; TÂNGARI, 2011, p.02).

Entende-se que, sob a visão de Rotta (2012) e Dischinger (2000), quando o pátio escolar é planejado sem considerar as relações entre arquitetura, atividades pedagógicas e teorias educacionais, há a formação de espaços inadequados para as atividades educacionais.

Estudos apresentados por Ribeiro et al. (2012) revelam que o ambiente físico determina, em grande parte, as experiências da criança, seu aprendizado e desenvolvimento, tendo as características físicas um papel muito importante.

A partir destas abordagens, o estudo realizado tem como objetivo analisar a organização dos pátios de escolas, com ênfase no uso e na apropriação pelos usuários. Procurouse investigar e observar quais aspectos dos pátios escolares interferem na apropriação espacial por parte dos estudantes. O foco da pesquisa está na observação e compreensão de como o usuário percebe e experimenta o ambiente, modificando-o ou não, aplicando técnicas e instrumentos de avaliação pós-ocupação para o desenvolvimento dessas análises.
Segundo Rheingantz et al. (2009), a Avaliação PósOcupação (APO) é um processo interativo, sistematizado e rigoroso de avaliação do desempenho do ambiente construído, passado algum tempo de sua construção e ocupação. Os conceitos e técnicas adotados fazem parte de um escopo para se absorver e compreender como a comunidade e usuários percebem, observam e interagem com o ambiente. Conforme Tavares Filho (2005), os resultados da APO podem servir de subsídios para novos projetos similares, com a intenção de não apresentarem os mesmos problemas já constatados, bem como para correção de projetos existentes.

Os procedimentos de análise do ambiente dos pátios escolares se dividiram em dois aspectos. Primeiramente, a análise objetiva (aspectos físicos e morfológicos), onde se realizou o mapeamento dos locais e levantamento de dados, com o objetivo de investigar os espaços livres existentes nas edificações elencadas. Ressalta-se que, devido aos projetos arquitetônicos não estarem disponíveis, tal procedimento foi realizado in loco, com auxílio de trenas. Em segundo lugar, realizou-se a análise subjetiva (aspectos subjetivos, simbólicos e culturais), na qual se analisa como se dá a ocupação das áreas livres, quais as atividades realizadas e o comportamento dos usuários, de acordo com suas vivências e experiências, havendo uma interação direta ou indireta entre $o$ pesquisador e os usuários.

Tais estudos são mutuamente complementares e auxiliam na obtenção dos objetivos da pesquisa. Ressalta-se que o artigo se desenvolveu a partir da análise subjetiva realizada de modo a responder as seguintes inquietações motivadoras: Como o estudante vê e sente o espaço? Quais anseios os usuários apresentam sobre o mesmo?

O artigo irá focalizar a construção e aplicação de três instrumentos pertencentes ao grupo de análise subjetiva mapa comportamental, mapa cognitivo e poema dos desejos, visando avaliar a ocupação destes espaços e compreensão dos mesmos segundo seus usuários. No decorrer da transcrição do artigo, serão apresentadas as etapas desenvolvidas durante a realização da análise subjetiva, dando ênfase à metodologia aplicada para a realização de tal estudo, bem como à pesquisa e síntese dos resultados obtidos a partir dos estudos de casos realizados em escolas públicas de ensino fundamental em Palmitinho, munícipio localizado na região noroeste do estado gaúcho.

Assim, são relatados os resultados parciais da pesquisa desenvolvida sobre apropriação espacial em pátios escolares, de forma a identificar os aspectos que podem interferir no processo de apropriação destes espaços por parte das crianças usuárias. 


\section{Fundamentação teórica}

A etimologia da palavra pátio - do latim: Pateo - define como: estar aberto; exposto; estender-se; abrir-se; estar descoberto; manifestar-se; ser evidente. As palavras sugerem o conceito de relacionamento com o ambiente físico, a cultura, as pessoas, etc.

Apesar da importância do pátio em termos de dimensão $\left(\mathrm{m}^{2}\right)$ e como local de atividade e interação social, na maioria das escolas brasileiras este espaço é omitido. Assim, os pátios escolares ainda são vistos apenas como um lugar onde as crianças podem ficar quando não estão desenvolvendo suas atividades em sala de aula, e por isso não seguem um projeto definido (FEDRIZZI, 2002).

O ministério da Educação não estabelece critérios específicos para a construção dos pátios das escolas. Sua única recomendação é que a área livre da escola deva ocupar pelo menos $50 \%$ do terreno disponível (BRASIL, 1985). Desta forma, não é suficiente julgar somente a área do terreno, também é preciso buscar a qualidade do espaço.

Outra característica que evidencia a noção existente do pátio escolar ser um espaço residual é que as atividades diversas de apoio ao processo pedagógico, entre elas as lúdicas, encontram-se dispersas no programa de atividades pedagógicas. Deve o "brincar" fazer parte do processo educativo. A atividade lúdica possibilita que a criança experimente, explore, desenvolva sua vivência com o mundo concreto e subjetivo. No entanto, os pátios e as áreas livres das escolas têm sido reduzidos ou até mesmo eliminados e, quando existem, são geralmente pouco convidativos ou acumulam outras funções, como extensão do refeitório e da área de circulação.

Nos locais e situações de brincadeira, a criança é agente de seu próprio desenvolvimento, na medida em que atua selecionando as suas atividades e objetos, seus lugares preferidos e seus colegas; por outro lado, ela também é influenciada pelo ambiente sócio físico em que se encontra, o que pode facilitar e alterar seus comportamentos. Conforme Sanoff (1994), um lugar com aparência de abandono e descuido é repelido pelas crianças, ao mesmo tempo em que, se bem conservado, contribui de forma positiva para o processo de sua apropriação. A forma de a criança agir, por sua vez, também modifica o ambiente.

Segundo Gonçalves e Flores (2011), uma boa arquitetura de pátio escolar deve atender as necessidades das crianças de: (a) estabelecer o contato social para permitir o desenvolvimento das habilidades de comunicação que não são permitidas em sala de aula, como o diálogo espontâneo ou o namoro, (b) brincar e jogar, atividades lúdicas que podem acontecer de maneira espontânea, além de desenvolver a capacidade do trabalho em equipe; (c) desenvolver a motricidade e os sentidos, que são atividades que permitem à criança conhecer-se melhor e ter um controle maior sobre o seu corpo, aumentando a autoestima e a confiança em si mesma; (d) complementar as funções pedagógicas - quando o espaço livre serve como exemplo ou complemento do conteúdo trabalhado em sala de aula e (e) aproximar-se do meio ambiente e da própria educação ambiental.

Assim, como espaço de aprendizagem, o pátio ideal deve possuir mais que quadras e parques infantis, que são equipamentos encontrados em outras edificações não escolares. Segundo Macedo et al. (2011), as decorações e murais comumente encontrados se mostram vazias diante o aluno sonhador e cheio de imaginação. Como conceito principal, o pátio precisa servir de local complementar ao aprendizado, procurando proporcionar transição entre espaços abertos ao ar livre e cobertos, oferecendo possibilidades diversas de usos e apropriações. Fedrizzi (1999) defende a necessidade de que o pátio da escola possua certos elementos e ofereça oportunidades e facilidades. Seriam eles: demonstrar cuidado, possibilitar a aprendizagem, dar oportunidades para brincar, oferecer segurança, possuir uma horta e pomar, ter a presença de vegetação, canchas para esportes, recantos ou esconderijos e abrigo contra intempéries.

Conforme Azevedo (2002), a setorização e organização não podem ser rigorosas, permitindo que a criança possa controlar e se apropriar desse ambiente. Entende-se que, quanto melhor for a qualidade do ambiente físico, maior será a qualidade de vida do usuário, tanto no aspecto psicológico quanto no físico, pois, se o ambiente não estiver adequado às necessidades do usuário, pode produzir consequências negativas a este (AZEVEDO; BASTOS, 2002; ELALI; PINHEIRO, 2003).

Ainda, segundo Kowaltowski (1989), muitos estudos constataram que, quando o espaço não está apropriado à satisfação e necessidades do usuário, principalmente nos aspectos de condições de acústica, higiene e densidade espacial, podem surgir tensão, angústia e estresse.

Neste pensamento, Rioli (2016) afirma que, para que o pátio obtenha êxito na sua função e uso, a interação com o ambiente deve possibilitar a construção de habilidades físicas, intelectuais e emocionais específicas a cada faixa etária. Conforme a autora deve-se considerar também às características das crianças (idade e gênero) e seu reflexo no uso do espaço.

No que tange as técnicas subjetivas elencadas para o desenvolvimento da pesquisa, Rheingantz et al. (2009), no livro Observando a Qualidade do Lugar, aborda o mapa cognitivo ou mapa mental, elaborado por Kevin Lynch nos anos 50. Este instrumento consiste na elaboração de desenhos ou relatos de memórias representativas das 
ideias que uma pessoa tem de um determinado ambiente, podendo ser preenchido através de desenhos ou escrita.

Deste modo, o mapa cognitivo se torna uma importante ferramenta para auxiliar na identificação de quais espaços e características das escolas analisadas que expressam valores visuais para seus usuários, demonstrando a visão que as crianças e jovens têm da mesma.

O mapa comportamental é um instrumento para registro das observações sobre o comportamento e as atividades em determinado ambiente (RHEINGANTZ et al., 2009). Este documento identifica os usos, as estruturas espaciais, o layout, os fluxos e os pontos de concentração dos usuários e suas relações comportamentais com o espaço observado. Este instrumento é recomendado especialmente na observação de ambientes utilizados por crianças. Sanoff (1996) considera a observação das crianças em suas atividades diárias a forma mais adequada para a compreensão do seu contexto ambiental.

Com relação ao poema dos desejos, este é um instrumento de pesquisa desenvolvido por Henry Sanoff (2001), no qual os usuários expressam graficamente, através de desenhos ou pela escrita, suas relações emocionais e expectativas sobre determinado ambiente. Tem como ponto de partida a sentença previamente proposta "Eu gostaria que o (edifício/ ambiente)...", tratando-se de um instrumento não estruturado e de livre expressão (RHEINGANTZ et al., 2009).

\section{Caracterização dos objetos de estudo}

Para que os objetivos inicialmente propostos na pesquisa sobre pátios escolares fossem obtidos, foram eleitos diferentes instrumentos de pesquisa com finalidade de compreender a organização espacial existente, as preferências dos usuários e as atividades realizadas nos diferentes espaços, entre outras informações relevantes.

Deste modo, na primeira aproximação foram identificadas sete escolas públicas que ofereciam Ensino Fundamental na cidade de Palmitinho/RS. Após visitação e observação destas escolas, foram escolhidas duas escolas que fizeram parte deste estudo: Escola Estadual de Ensino Fundamental Olavo Bilac e Escola Municipal de Ensino Fundamental Castro Alves. Os critérios levados em consideração para a seleção das escolas foram as características físicas do local, sendo que, foram levantados os usos e atividades dos pátios, tais como área de jogos, brincadeiras, quadras esportivas, playground, espaço verde. Desta forma, selecionaram-se estas duas escolas em função do maior número de atividades realizadas no pátio.

Posteriormente, foi aplicada a combinação de diferentes instrumentos metodológicos, a partir da observação do comportamento e impressões sobre o ambiente através dos instrumentos mapa comportamental, "poema dos desejos" e mapa cognitivo.

O mapa comportamental foi realizado com representações gráficas das interações e comportamentos, registrados pelo observador, entre o usuário e o ambiente. Optou-se por trabalhar em um formato A3, através de planta baixa do pátio e espaço para observações pessoais. Os mapas têm por base Martins (2013) e foram adaptados de Sanoff (2001).

O "poema dos desejos" e o mapa cognitivo foram elaborados em folhas de tamanho A4, contendo cabeçalho com identificação do projeto de pesquisa, local para identificação da turma e nome do respondente, itens sem obrigatoriedade de preenchimento, e mantendo a maior superfície em branco possível na folha para que fosse desenvolvido o desenho/texto por parte de cada criança.

A aplicação destes instrumentos de análise se deu com $20 \%$ dos estudantes do Ensino Fundamental $\left(1^{\circ}\right.$ a $9^{\circ}$ ano), previamente selecionados pelos professores responsáveis das turmas, tendo em vista a necessidade do preenchimento do termo de participação do aluno pelos pais ou responsáveis, num total de 40 participantes, com idade entre 6 e 14 anos. O termo de consentimento foi enviado para os pais dos alunos selecionados. Ressalta-se que se pretendia realizar a aplicação dos instrumentos com um número maior de alunos, mas esta se tornou inviável devido à necessidade de assinatura do termo de consentimento, conforme relatado.

Destaca-se ainda que, a aplicação das técnicas ocorreu em espaço disponibilizado pelas respectivas instituições de ensino, durante o período das aulas, sendo os alunos liberados a partir do consentimento dos professores. A conversação inicial deu-se com a apresentação do pesquisador e uma conversa descontraída sobre a aula em que estavam quando da liberação. Posteriormente, explicou-se o instrumento do Mapa cognitivo, deixando os alunos com um tempo livre para realização da atividade. Em um segundo momento, a atividade prosseguiu com a aplicação do Poema dos Desejos, vislumbrando um maior entusiasmo dos alunos, que exploraram sua imaginação.

Houve uma boa interação entre pesquisadores e professores das instituições em estudo, havendo uma colaboração destes quando do levantamento de campo e da aplicação dos instrumentos com os alunos, sendo os resultados posteriormente apresentados por escola investigada.

\section{Escola Estadual de Ensino Fundamental Olavo Bilac}

A escola, inaugurada em 1958 com o objetivo de atender ao Ensino Fundamental, localiza-se na Linha Boa Vista, interior de Palmitinho-RS, distante $3 \mathrm{~km}$ do centro da cidade. Por ocasião do estudo, a escola contava com 70 
alunos e está localizada em área de uso predominantemente residencial, com poucos serviços, incluindo mercado e uma fábrica de pré-moldados (Figura $1)$.

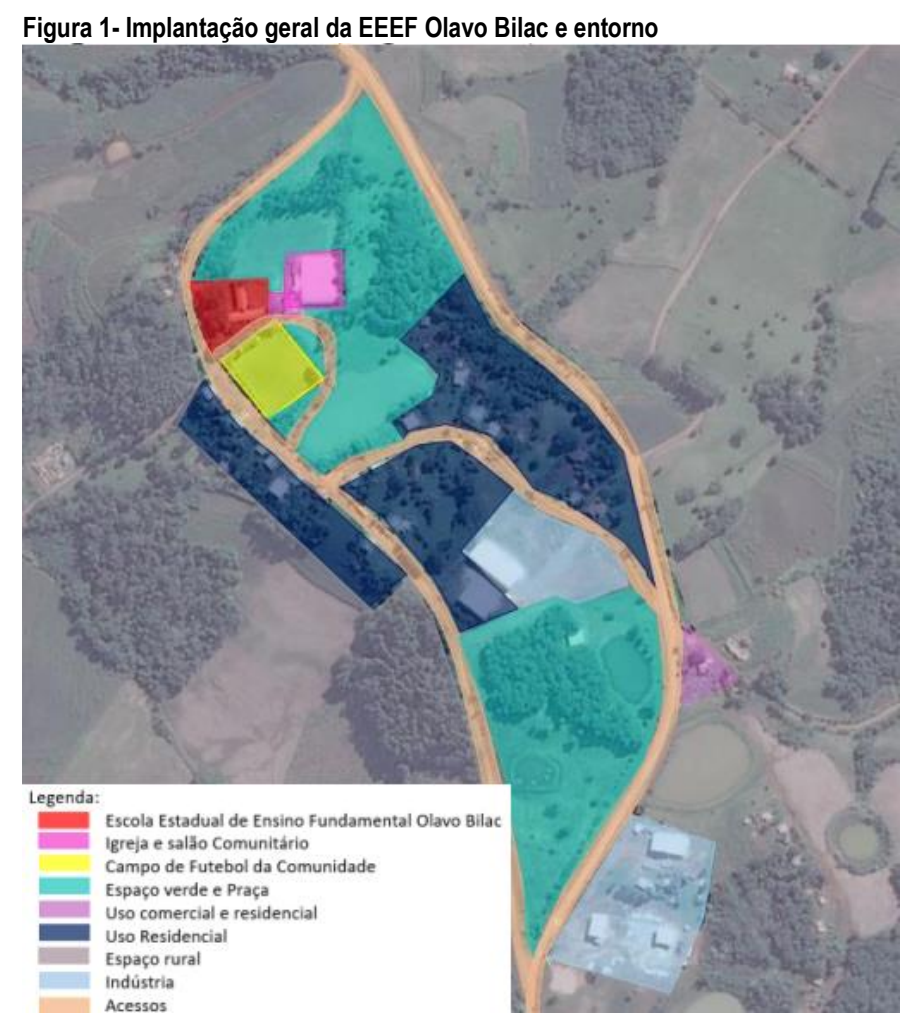

Fonte: As autoras, adaptado de Google Earth.

Evidencia-se que a edificação da escola está situada em um terreno com $2.551,30 \mathrm{~m}^{2}$ e possui área construída de $426,85 \mathrm{~m}^{2}$ (Figura 2). O restante do lote é ajardinado, possui um playground e espaço com vegetação de médio porte. Ao observar a implantação da escola no lote, o pátio foi subdividido em três, sendo o pátio de acesso principal demarcado como pátio 01, acesso secundário e uma grande área livre arborizada como pátio 02 e o pátio 03 foi atribuído ao campo de futebol, situado ao lado da escola. Apesar de não pertencer à escola, este campo foi incluído nas análises por ser ambiente frequentemente utilizado pelos alunos durante o intervalo entre aulas.

\section{Escola Municipal de Ensino Fundamental Castro Alves}

A Escola Municipal de Ensino Fundamental Castro Alves foi inaugurada no ano de 1960 e oferece ensino a 146 alunos nas modalidades: Ensino Infantil, Ensino Fundamental e Educação de Jovens e Adultos (EJA). Localiza-se na Linha Esquina do Comércio, interior de Palmitinho-RS, está distante $9 \mathrm{~km}$ do centro da cidade e o acesso é pela RSC 472. O uso do solo nesta região é predominantemente residencial (Figura 3).
Figura 2 - Planta de implantação da EEEF Olavo Bilac com divisão dos pátios.

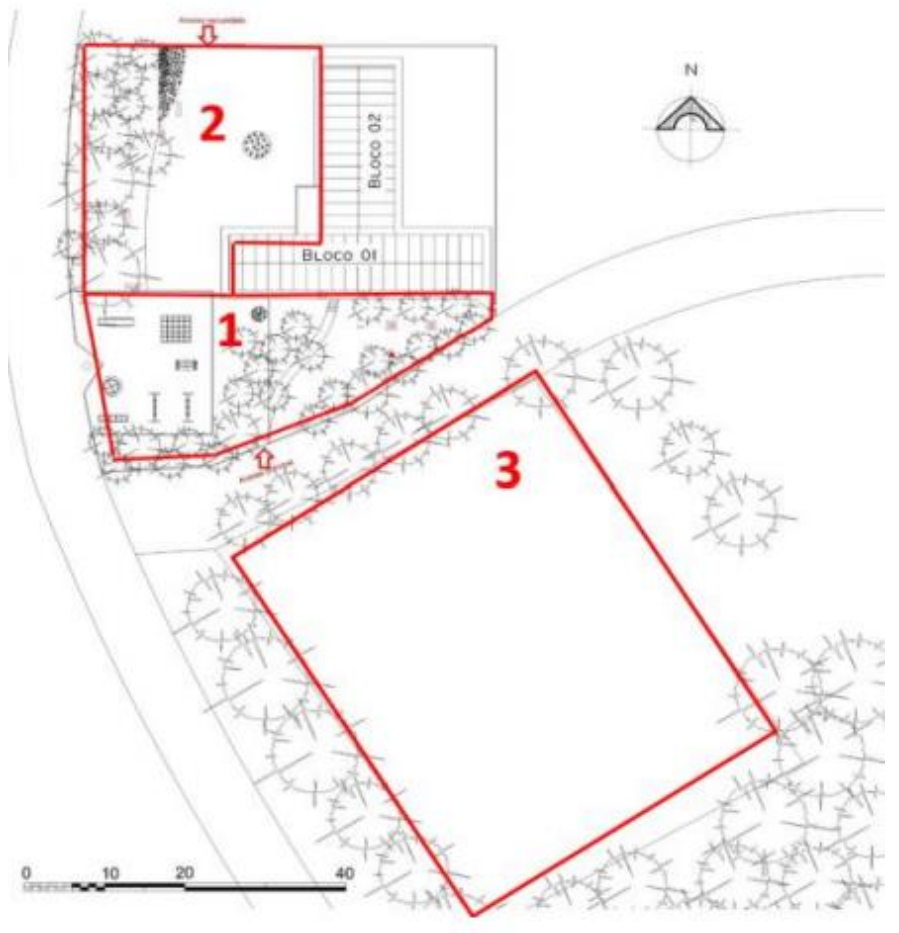

Fonte: Rech (2017).

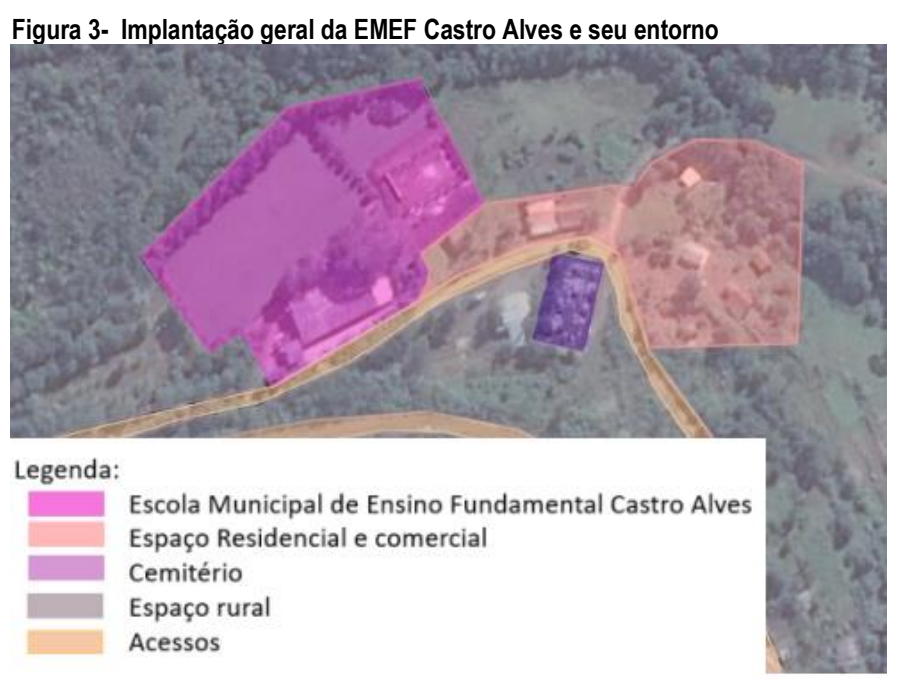

Fonte: As autoras, adaptado de Google Earth.

A edificação da EMEF Castro Alves está situada em um terreno com 7.890,00 $\mathrm{m}^{2}$ e possui área construída de $1190,00 \mathrm{~m}^{2}$. O restante do lote é ajardinado, apresentando um playground, campo de futebol e ginásio de esporte (Figura 4). A área da escola foi dividida em três pátios, sendo que o pátio de acesso principal foi demarcado como pátio 01 . O pátio 02 foi definido onde estão localizados o playground e a área livre arborizada. $\mathrm{O}$ pátio 03 foi demarcado como o espaço livre com vegetação em meio aos espaços de esporte, como campo de futebol e ginásio esportivo. O ginásio poliesportivo não foi considerado quando da aplicação do mapa comportamental, devido ao fato do mesmo ser comunitário e usado de forma ocasional em dias chuvosos pela instituição de ensino. 


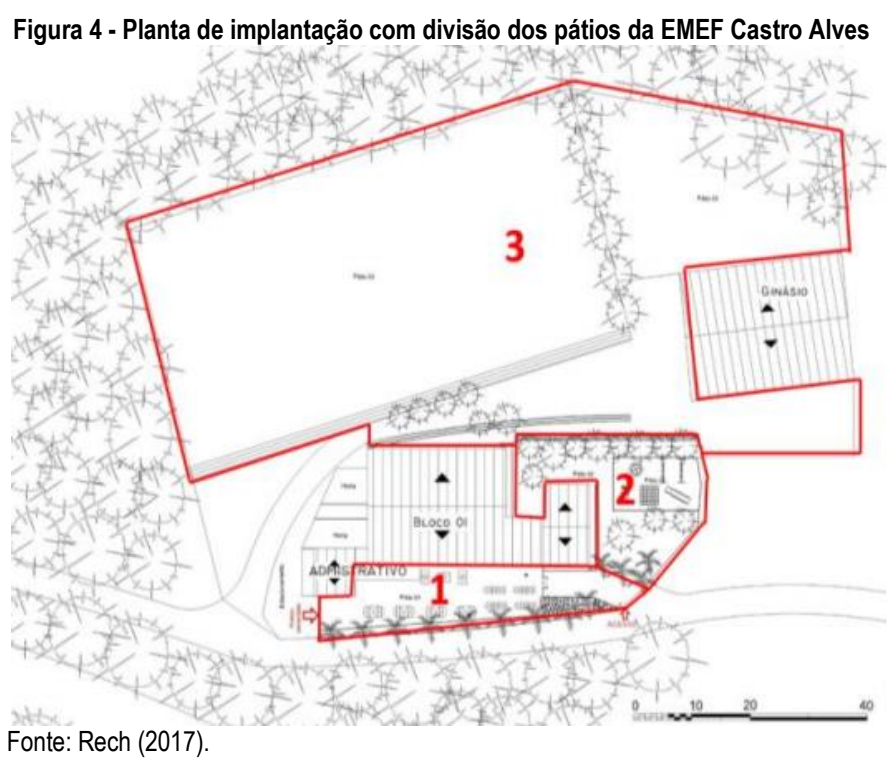

\section{Métodos de investigação e discussão dos resultados}

Após a seleção das escolas para fins de observação e análise, a concessão de autorização do estudo das mesmas por parte das direções e as assinaturas dos participantes dos termos de livre consentimento, documentos exigidos por lei para pesquisas envolvendo pessoas, foi iniciado o processo de levantamento dos estudos de caso. O nível de aprofundamento e a quantidade de informações coletadas em cada escola não foram os mesmos, por conta das diferenças contextuais de cada estudo de caso. Os instrumentos de análise foram aplicados conforme um planejamento de visitas.

A primeira etapa de levantamento deu-se com a realização das visitas exploratórias e de leitura espacial e, posteriormente, com a aplicação do mapa comportamental e a elaboração do "poema dos desejos" e do mapa cognitivo, sendo os resultados dos mesmos apresentados na sequência. Ressalta-se que a participação dos alunos, quando da aplicação dos instrumentos poema dos desejos e mapa cognitivo, foi consentida previamente pelos pais dos mesmos, a partir da assinatura do termo livre de consentimento. Verificou-se, quando da aplicação dos instrumentos, uma grande curiosidade por parte dos alunos participantes ou não da investigação, que se mostraram solícitos a colaborar e desenvolver as atividades propostas pelos pesquisadores.

\section{Mapa comportamental}

Na EEEF Olavo Bilac, os pátios 01 e 02 possuem área arborizada (Figuras 05 e 06), porém não são utilizados. $\mathrm{O}$ playground, situado ao lado do pátio 01, apresenta mobiliários degradados e está fechado, porém, possui recortes na tela que possibilitam que os alunos acessem o espaço sem permissão.

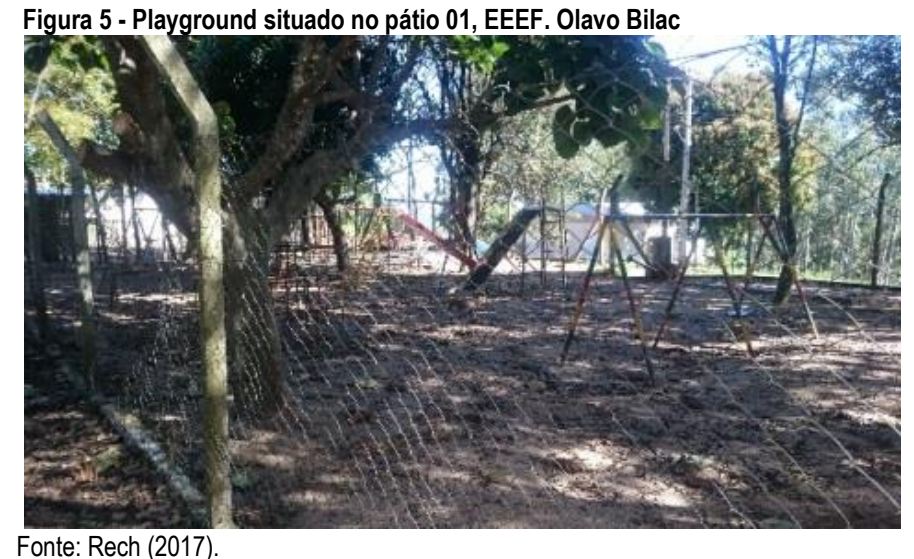

Fonte: Rech (2017).

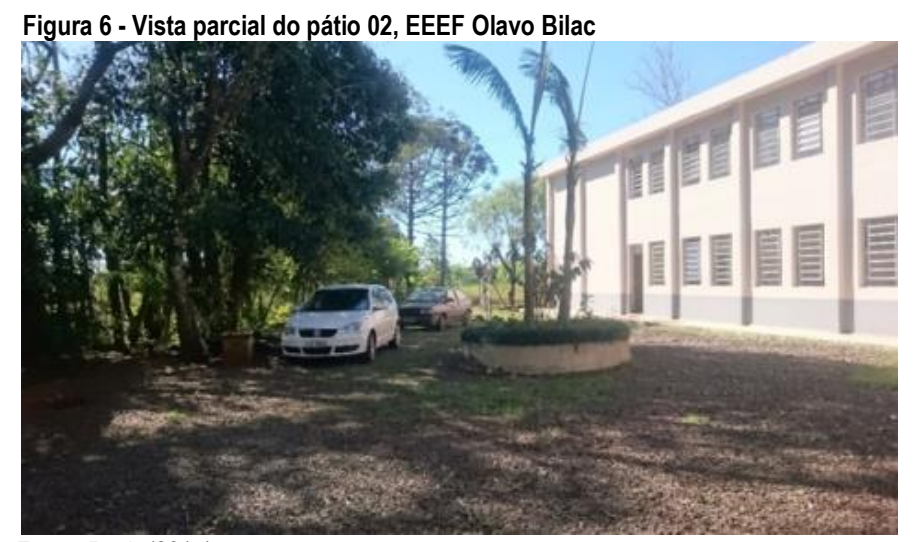

Fonte: Rech (2017).

Entre os três pátios, apenas o pátio 03 apresentou movimentação mais relevante, a qual se prolonga ao campo de gramado da comunidade, que serve de espaço de recreação para as crianças e para a realização de diversas atividades (Figura 7). Não há a presença de bancos no local e as brincadeiras são realizadas de forma livre. Ainda, este é o único espaço da escola onde há a presença de um professor responsável durante o intervalo, período no qual observa as atividades dos alunos.

Na análise da ocupação dos pátios na EMEF Castro Alves (Figura 8), verificou-se que as crianças se apropriam do espaço fazendo a utilização dos desníveis como bancos e das árvores como recantos para conversas e realizando atividades mais estáticas.

No pátio 02 (Figura 9), onde está localizado o playground, há movimentação intensa, sendo o uso deste espaço liberado no intervalo das aulas. Não foi observada, na ocasião, nenhuma atividade no pátio 03 .

Em ambas instituições de ensino, verificou-se que a ocupação do espaço não é fortemente influenciada pelos mobiliários, quando estes existem, mas sim que a apropriação dos mesmos se dá de forma livre e espontânea, onde os alunos adaptam a realidade existente em consonância com seus anseios e brincadeiras. 


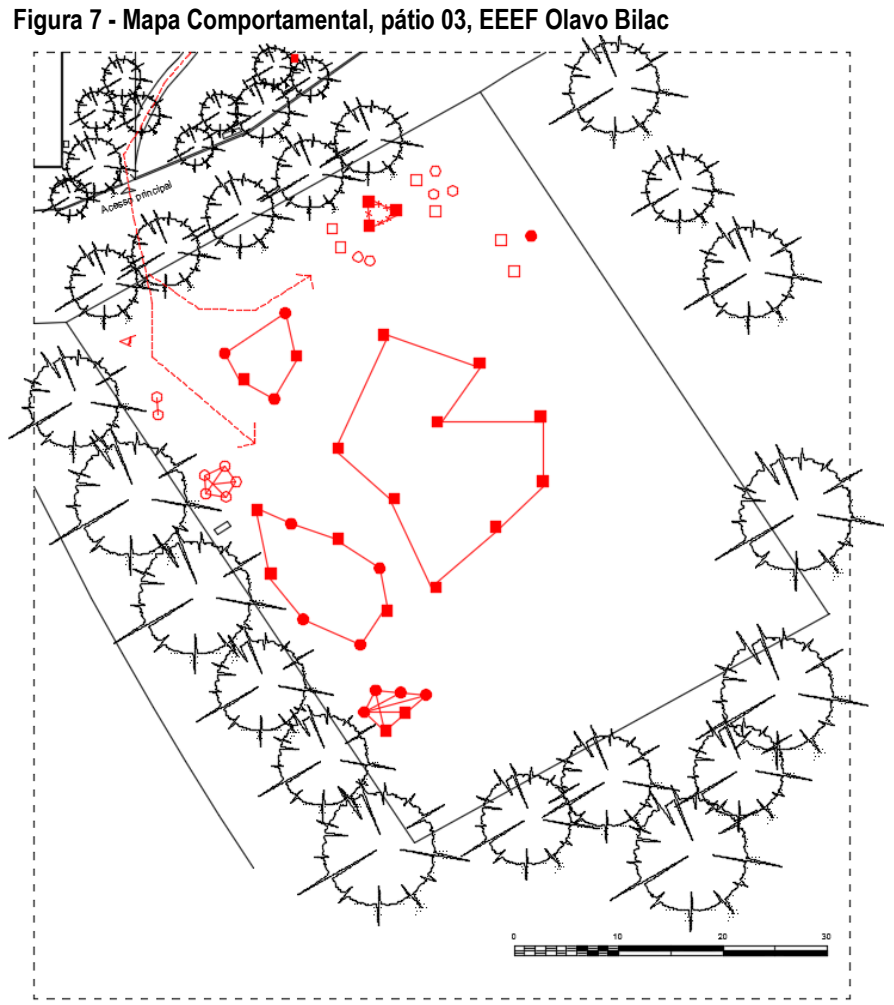

Legenda

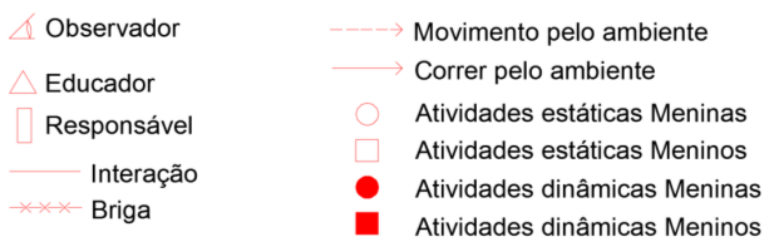

Fonte: Adaptado de Martins (2013).

Figura 8 - Mapa Comportamental, pátio 01, E.MEF Castro Alves

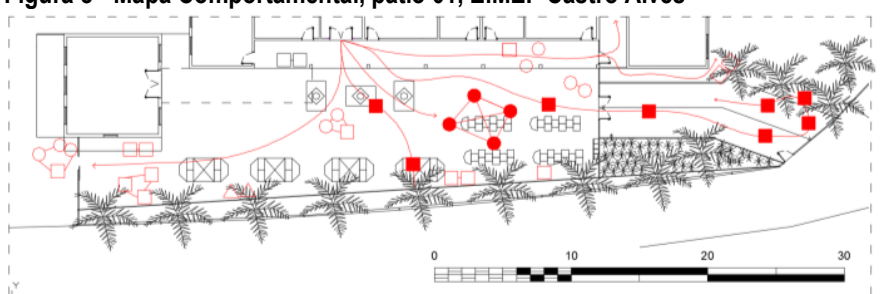

Legenda

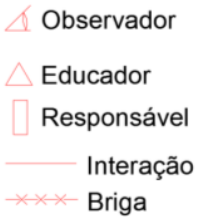

Fonte: Adaptado de Martins (2013).

\section{Mapa cognitivo e poema dos desejos}

Tendo em vista que o mapa cognitivo e o poema dos desejos constituem-se em ferramentas não estruturadas, as respostas obtidas são, em muitos casos, subjetivas, o que torna mais complexo o processo de tabulação dos resultados.
Figura 9: Mapa Comportamental, pátio 02, EMEF Castro Alves

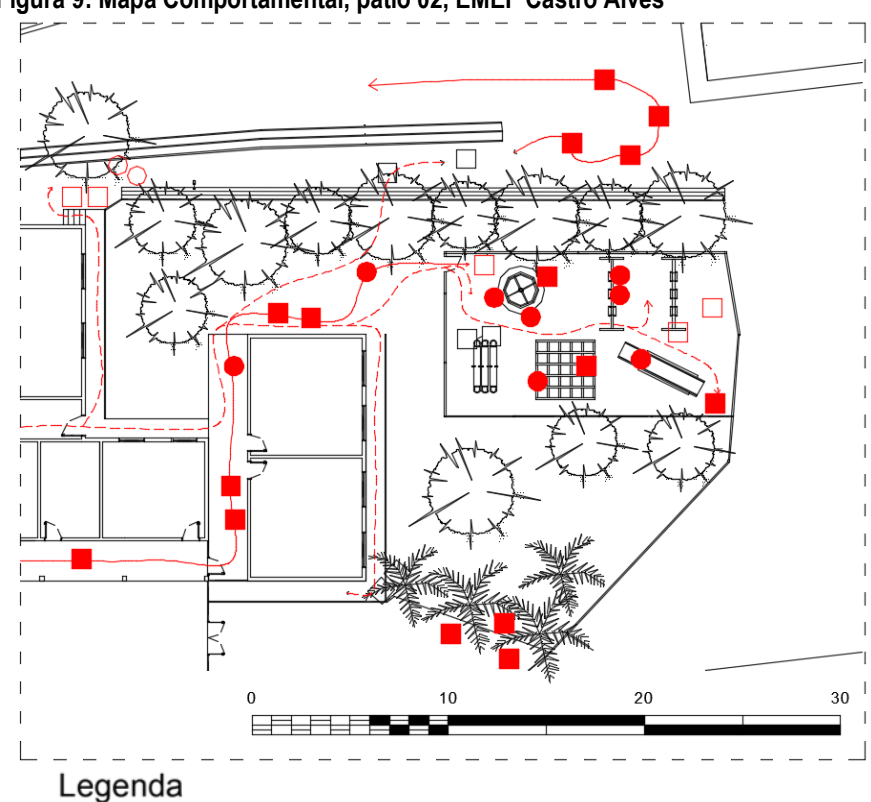

Movimento pelo ambiente Correr pelo ambiente Atividades estáticas Meninas Atividades estáticas Meninos

- Atividades dinâmicas Meninas

- Atividades dinâmicas Meninos

Fonte: Adaptado de Martins (2013).

Em uma primeira etapa da análise, os resultados, tanto do mapa cognitivo como do poema dos desejos, foram separados por turmas em cada escola. Uma vez que $20 \%$ dos alunos, para cada escola, entre $1^{\circ}$ a $9^{\circ}$ ano participaram da aplicação dos instrumentos, a separação dos mesmos se deu em duas categorias: de $1^{\circ}$ ao $5^{\circ}$ ano e de $6^{\circ}$ ao $9^{\circ}$ ano e, em seguida, à categorização dos elementos gráficos conforme a recorrência dos desenhos/textos.

Deste modo, a fim de facilitar o ordenamento dos resultados, optou-se pela categorização das respostas em grupos, a saber: (a) ambiente físico/infraestrutura (espaços internos, espaços externos, ginásio, campo de futebol...), (b) elementos concretos (brinquedos...) (c) elementos afetivos/ lúdicos e atividades (relação entre alunos, harmonia, brincadeiras, música...), (d) elementos da natureza (água, animais, árvores e plantas...). Esta divisão foi feita de modo que, a partir da tabulação dos resultados, fossem originados gráficos que facilitassem a leitura e a análise, traduzindo os elementos mais significativos na cognição dos usuários. Para demonstrar os resultados do mapa cognitivo e poema dos desejos nas duas escolas em estudo, optou-se pela apresentação dos resultados obtidos para cada escola a partir da aplicação de ambos os instrumentos, com os alunos de $1^{\circ}$ a $9^{\circ}$ ano.

Assim, na EEEF Olavo Bilac, os 15 alunos que participaram deste instrumento (20\% do total de alunos da instituição), elencaram principalmente os elementos 
físicos (Gráfico 1), como exemplo a edificação escolar e a cobertura existente no caminho que une o portão de entrada ao prédio institucional, que havia sido executada por ocasião do levantamento (Figura 10). Dos elementos afetivos e atividades realizadas, destaca-se a boa interação e relacionamento entre alunos e educadores, bem como o uso frequente do campo comunitário para atividades de recreação. Evidenciou-se, durante o levantamento que, muitas vezes, mais de um dos elementos adotados para fins de análise foi abordado pelos alunos envolvidos na atividade. Para realizar o levantamento quantitativo, contabilizou-se o elemento que apresentou maior destaque na resposta dada a cada instrumento aplicado.

\section{Gráfico 1 - Mapa Cognitivo EEEF Olavo Bilac}

\section{Mapa Cognitivo}

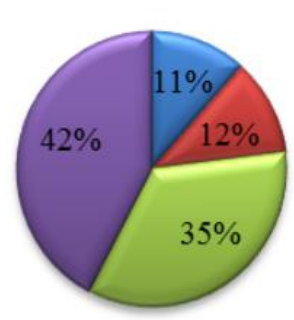

Fonte: As autoras

Figura 10 - Resultado obtido com poema dos desejos na EEEF Olavo Bilac

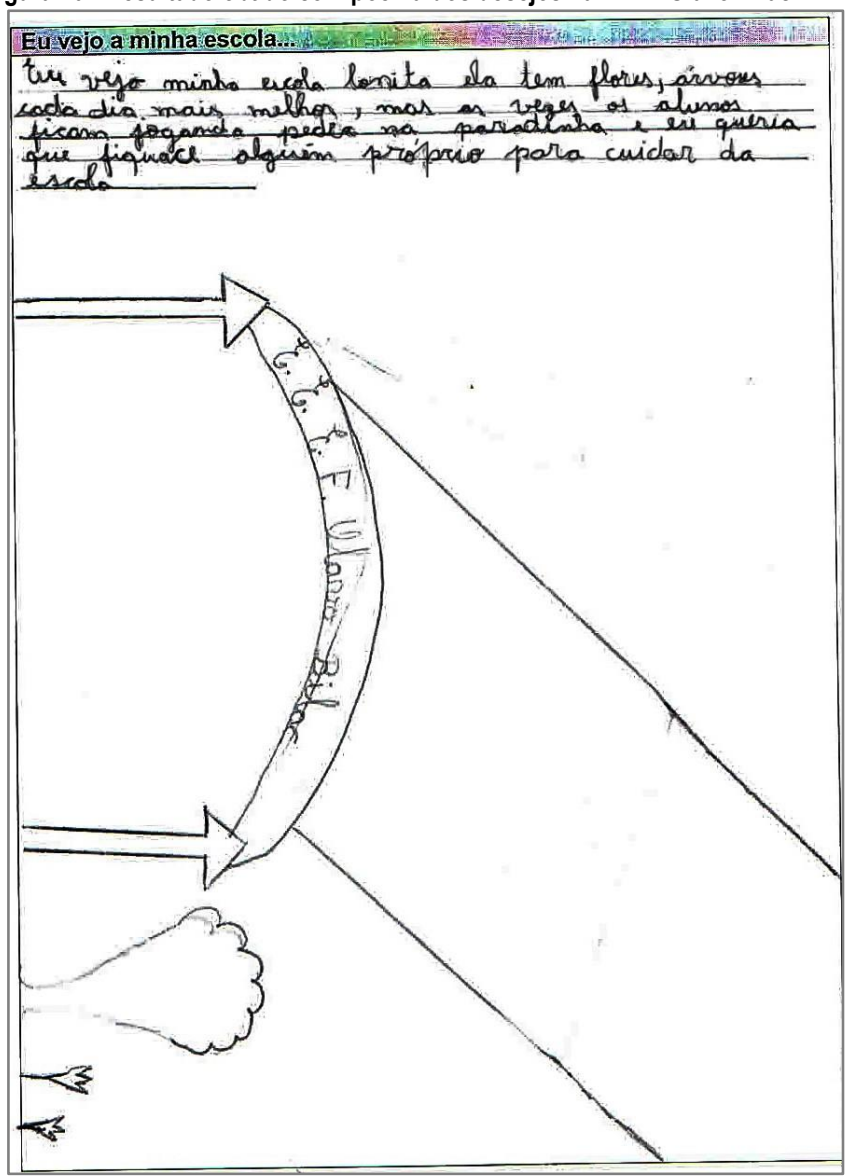

Fonte: Registo da pesquisa. afetivos/lúdicos/atividades

$\square$ Ambiente físico/infraestrutura

Elementos concretos

$\square$ Elementos
Elementos da natureza

Durante a aplicação da técnica do "poema dos desejos", ficou evidenciado que o elemento mais considerado está relacionado ao ambiente físico e infraestrutura da escola (Gráfico 2), com destaque para salas de atividades e laboratórios, e, posteriormente, de elementos concretos, relacionados principalmente à recreação (Figura 11). Nesta atividade, também se verificou a abordagem de mais de um elemento por aluno, utilizados enquanto o desenvolvimento da técnica e para fins de análise gráfica da técnica, e considerado o elemento de maior importância destacado pelo aluno quando da realização do método.

\section{Gráfico 2 - Mapa "poema dos desejos" EEEF Olavo Bilac}

\section{Poema dos Desejos}

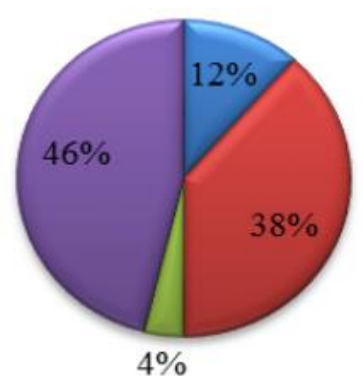

Elementos da natureza

Elementos concretos

$\square$ Elementos afetivos/lúdicos/atividades

Fonte: As autoras.

Ambiente físico/infraestrutura

Figura 11 - Poema dos desejos $2^{\circ}$ ano EEEF Olavo Bilac

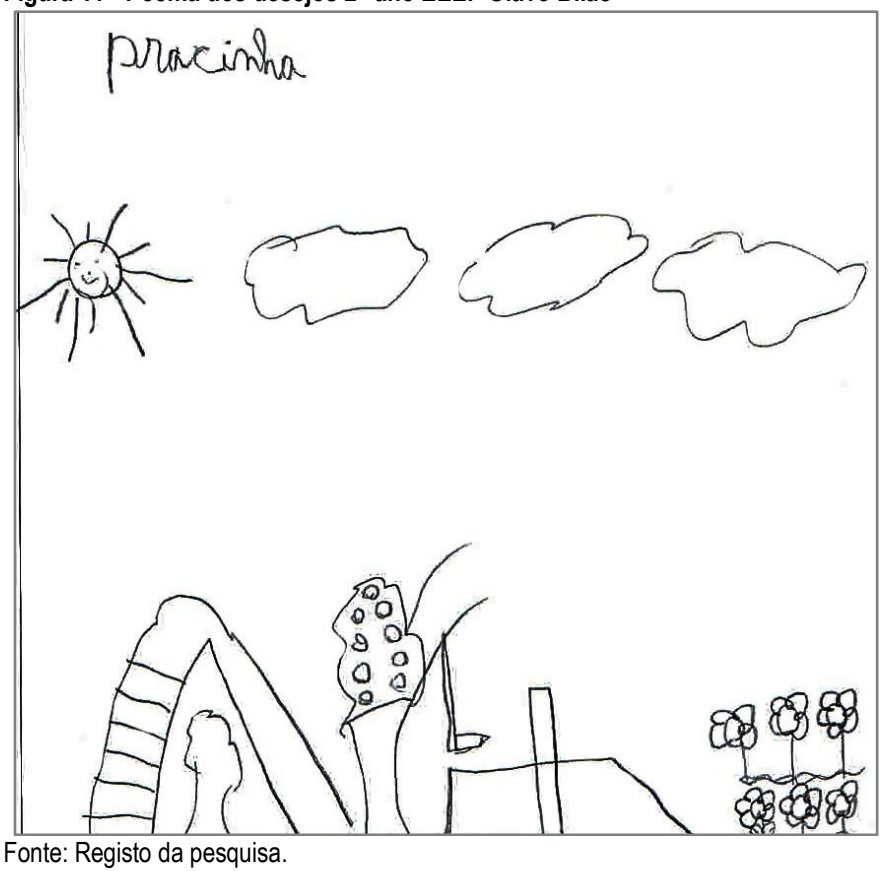

Na EMEF Castro Alves, o elemento de maior destaque foi o afetivo (Gráfico 3), onde os 25 alunos que participaram quando da aplicação do instrumento revelaram grande apreço pelo ambiente educacional (elementos afetivos), efeito do bom relacionamento entre alunos, professores e funcionários, constatado durante as visitas, revelando grande aproximação e carinho entre os mesmos (Figura 
12). Dentre os elementos afetivos, lúdicos e atividades, também se destacam algumas atividades realizadas pelos alunos, como jogos de futebol e brincadeiras no pátio, por exemplo, pega-pega, fortalecendo as trocas interpessoais.

Gráfico 3 - Mapa cognitivo EMEF Castro Alves

Mapa Cognitivo

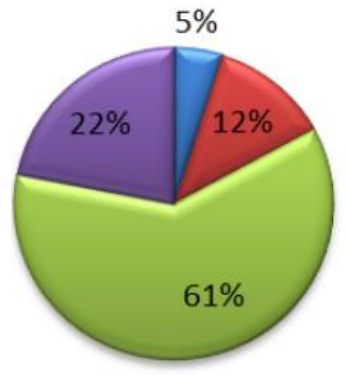

Elementos da natureza

$\square$ Elementos concretos

$\square$ Elementos

afetivos/lúdicos/atividades

Ambiente

físico/infraestrutura

Fonte: As autoras.

Com relação à técnica "poema dos desejos" na EMEF. Castro Alves, a maioria dos alunos demonstrou anseios por melhorias e investimentos na infraestrutura da escola (Gráfico 4). Cita-se como exemplo a solicitação de aumento de área do pátio calçado existente na frente da edificação escolar, em virtude de o pátio gramado não poder ser usufruído nos dias úmidos. Outro exemplo é o pedido da construção de uma piscina para aulas de natação e de pista de skate, tendo em vista o apreço dos alunos por tais atividades.

Figura 12 - Apresentação de resultados obtidos com poema dos desejos na EMEF Castro Alves

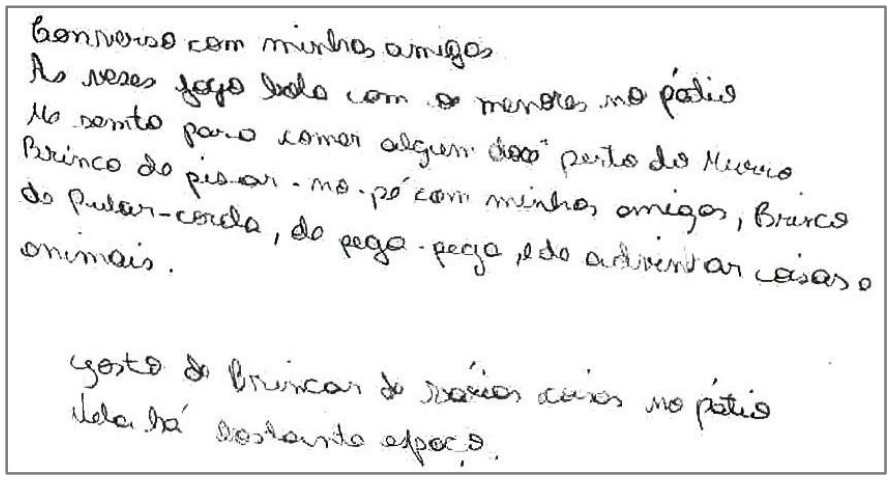

Fonte: Registo da pesquisa

Gráfico 4 - Mapa "poema dos desejos" EMEF. Castro Alves Poema dos Desejos

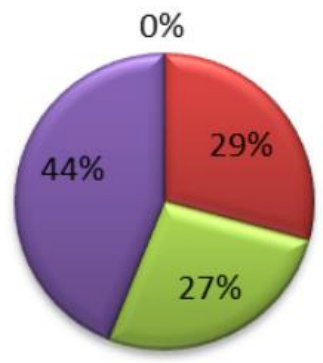

Elementos da natureza

घElementos concretos

Elementos afetivos/lúdicos/atividades

Ambiente físico/infraestrutura
No que tange aos elementos concretos, a ausência de bancos no pátio externo foi um dos principais quesitos abordados (Figura 13), tendo em vista que, conforme verificado no mapa cognitivo, a questão de trocas interpessoais e laços afetivos foram fortemente demonstrados. A presença de inspetor/professor no pátio, para proporcionar segurança e tranquilidade dos alunos, também foi aspecto solicitado pelos usuários.

Figura 13 - Poema dos Desejos $6^{\circ}$ ano EMEF Castro Alves

\begin{tabular}{|c|}
\hline 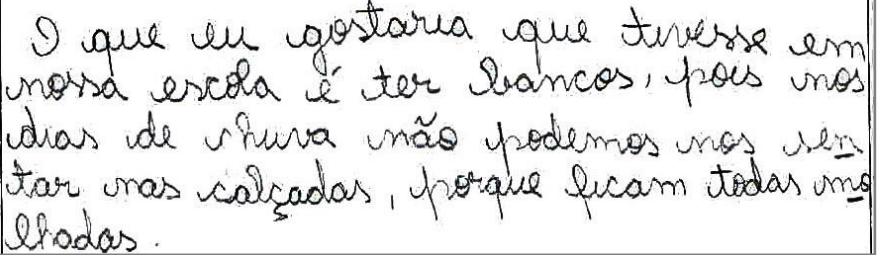 \\
\hline
\end{tabular}

Fonte: Registo da pesquisa.

\section{Comparação entre as descobertas}

Analisando a presença de elementos da natureza, nos dois estudos de caso há árvores no pátio, sendo a interação das crianças com esses elementos ainda restrita, pois geralmente as mesmas apenas usufruem da sombra e observam as flores.

Já para as crianças de 12 anos em diante, segundo os resultados dos mapas comportamentais, estas estavam concentradas em atividades mais estáticas e utilizavam espaços sombreados com bancos para socialização de grupos. Nos resultados dos "poemas dos desejos", a maioria das crianças desta faixa etária revelava desejar que existissem mobiliários no pátio e espaços para atividades desportivas.

Reforça-se assim o ideal defendido por Elali (2003), que afirma que as áreas externas devem sempre estar equipadas com bancos para o descanso, bate-papo e pequenos agrupamentos. O mobiliário disponibilizado nos pátios assim como suas disposições são fatores importantes no uso do espaço.

A EEEF Olavo Bilac possui poucos bancos, sendo estes localizados em espaço arborizado, contudo com chão batido sem manutenção e limpeza. Já a EMEF Castro Alves não possui mobiliários nos pátios, sendo um item citado frequentemente pelos alunos no levantamento realizado.

Frente à não apropriação de grande parte do pátio pelos alunos, como demonstrado pelos mapas comportamentais apresentados, Fedrizzi (1999) sugere que áreas muito extensas sejam divididas em partes menores, especialmente no caso de crianças pequenas. Essa divisão torna o ambiente mais aconchegante e evita o desuso de grandes espaços. Ambientes variados favorecem 
diferentes formas de interação entre pessoa/ambiente e estimulam o uso e apropriação do espaço pelos usuários.

Nos resultados dos "poemas dos desejos", muitas crianças revelaram o desejo de que houvesse mais brinquedos e/ou fosse feita manutenção dos brinquedos existentes no playground. Pode-se pensar em um espaço destinado à colocação de objetos e materiais soltos que permitam a intervenção do usuário no espaço, reorganizando-o ou desenvolvendo novos usos para os brinquedos, estimulando o inventar, o uso e a apropriação do espaço.

Assim, fica constatada a importância de ouvir as crianças usuárias dos ambientes, quando possível, para perceber o quanto são capazes de emitirem críticas, expressando suas necessidades e sugestões criativas quanto à melhoria do ambiente construído.

\section{Considerações finais}

Pensar sobre os espaços de brincadeira e sua importância para o crescimento saudável das crianças é essencial para que se construam locais adequados às necessidades infantis. Levando em consideração tais aspectos, alerta-se para a necessidade de uma maior atenção no planejamento e organização do pátio escolar, no sentido de promover a diversidade comportamental essencial ao pleno desenvolvimento infantil, prever diferentes usos do espaço em função da idade e do gênero das crianças (mas sem separá-las por nível ou idade), permitir brincadeiras passivas e ativas, em grupos ou individuais, sempre em função das necessidades e escolhas de cada um.

Nos pátios escolares, o processo de interação entre as crianças é bastante interessante, pois assume características distintas da sala de aula, possibilitando aos alunos relacionarem-se com outros colegas. Desta forma, o levantamento realizado nas instituições de ensino público fundamental aqui abordado confirma a importância da participação do usuário para a obtenção de espaços arquitetônicos de qualidade.

Assim, a participação dos usuários é extremamente importante na descoberta de aspectos que somente os mesmos podem perceber, tendo em vista que estes podem não ser significativos para os pesquisadores/observadores, mas que são marcantes e repletos de significados para quem experencia aquele espaço no cotidiano. Da mesma forma, o pesquisador/observador contribui ao interagir com o espaço e o usuário, apontando aspectos negativos que passam despercebidos por quem está acostumado com tal espaço.

Buscando contribuir para o entendimento do uso e apropriação dos pátios escolares pelos alunos, sugerimos a ampliação do número de pátios escolares a serem observados, incorporando os demais espaços do ambiente escolar.

\section{Agradecimentos}

A todos os funcionários e participantes das escolas de Ensino Fundamental onde foram realizados os estudos de casos, por colaborarem com esta pesquisa, pela disponibilidade e pelas informações prestadas.

\section{Referências}

AZEVEDO, G. A. N.; BASTOS, L. E. Qualidade de vida nas escolas: produção de uma arquitetura fundamentada na interação usuário-ambiente. In: DEL RIO, V.; DUARTE, C. R.; RHEINGANTZ, P. A. (Orgs.), Projeto do lugar: colaboração entre psicologia, arquitetura e urbanismo. Rio de Janeiro: ContraCapa/PROARQ. 2002, p. 153-160.

AZEVEDO, G. A. N.; RHEINGANTZ, P. A.; TÂNGARI, V. R. (Orgs). O lugar do pátio escolar no sistema de espaços livres: uso, forma e apropriação. Rio de Janeiro, UFRJ/FAU/PROARQ, 2011. 203 p. (Coleção PROARQ)

BRASIL, Ministério da Educação e da Cultura. Secretaria Geral. Centro de Desenvolvimento e Apoio Técnico à Educação (CEDATE). Manual para construções escolares. Brasília: MEC/SEF, 1985.

DISCHINGER, M. Designing for al senses: accessible spaces for visually impaired citizens. 2000. 260f. Thesis (Doctor of Philosophy) - Department of Space and Process School of Architecture, Chalmers University of Technology, Göteborg, Suécia, 2000.

ELALI, Gleice Azambuja. O ambiente da escola - o ambiente na escola: uma discussão sobre a relação escola-natureza em educação infantil. Estud. psicol. (Natal), Natal, v. 8, n. 2, p. 309-319, Aug. 2003. doi:http://dx.doi.org/10.1590/S1413294X2003000200013.

ELALI, G. A.; PINHEIRO, J. Q. Edificando espaços, enxergando comportamentos. In: MARQUES, S.; LARA, F. (Orgs.), Projetar: desafios e conquistas da pesquisa e do ensino de projeto. Rio de Janeiro: EVC. 2003, p. 130-144. 
FEDRIZZI, B. Paisagismo no pátio escolar. Porto Alegre: Editora da Universidade Federal do Rio Grande do Sul. 1999.

FEDRIZZI, B. A Organização Espacial em Pátios Escolares Grandes e Pequenos, In: DEL RIO, V.; DUARTE, C.; RHEINGANTZ, P. A. (Orgs). Projeto do Lugar: Colaboração entre Psicologia, Arquitetura e Urbanismo. Rio de Janeiro: ContraCapa/PROARQ, 2002, p 221-229.

GONÇALVES, F. M.; FLORES, L. R. Espaços livres em escolas: questões para debate. In: AZEVEDO, G. A. N.; RHEINGANTZ, P. A.; TÂNGARI, V. R. (Org.). O lugar do pátio escolar no sistema de espaços livres: uso, forma e apropriação. Rio de Janeiro, UFRJ/FAU/PROARQ. v.1, 2011, p.23-33.

KOWALTOWSKI, D. K. Arquitetura escolar. O projeto do ambiente de ensino. São Paulo, Oficina de Textos, 2011.

KOWALTOWSKI, D. C. C. K. Arquitetura e humanização. Projeto, 126, 129-132. 1989.

MACEDO, S. S.. Prefácio. In: AZEVEDO, G. A. N.; RHEINGANTZ, P. A.; TÂNGARI, V. R. (Org.). O lugar do pátio escolar no sistema de espaços livres: uso, forma e apropriação. Rio de Janeiro, UFRJ/FAU/PROARQ, 2011. 203 p. (Coleção PROARQ).

MARTINS, V. R. O lugar do pátio escolar: reunindo descobertas produzidas na observação de quatro escolas públicas do município do Rio de Janeiro. 2013. Dissertação (Mestrado) - Faculdade de Arquitetura e Urbanismo, Universidade Federal do Rio de Janeiro, Rio de Janeiro, 2013.

NORBERG-SCHULZ, C.; DIGERUD, J. G. (colaboração). Louis I. Kahn, Idea e imagen. Madrid: Xarait editiones, 107 p., il. 1981.

RECH, G.R.da F. Apropriação espacial em pátios escolares de Ensino Fundamental Público em Palmitinho-RS. 2017.229 f. Dissertação (Mestrado em Arquitetura e Urbanismo) - Universidade Federal de Santa Catarina, Florianópolis, 2017.

RHEINGANTZ, P. A.; AZEVEDO, G.; BRASILEIRO, A.; ALCANTARA, D.; QUEIROZ, M. Observando a Qualidade do Lugar: procedimentos para a avaliação pós-ocupação. Rio de Janeiro: FAU-UFRJ (Coleção PROARQ), 2009.

RIBEIRO, A.C.S.; SOARES, G.L.; VILHENA, T.F.P.; MUNHOZ, J.M.; STEFENON, V.M. Qualidade de vida no ambiente escolar como componente da formação do cidadão: desejos e carências no espaço físico. Monografias Ambientais, v. 8, n. 8, p. 1850-1857, ago. 2012. doi:http://dx.doi.org/10.5902/223613086192.

RIOLI, T.O. Pátio escolar coberto: a qualidade ambiental, estética e funcional em escolas de Educação Infantil.2016. 104 f. Dissertação (Mestrado) - Faculdade de Arquitetura, Artes e Comunicação, Universidade Estadual Paulista, Bauru, 2016. http://hdl.handle.net/11449/144671

ROTTA, M. B. A qualidade do lugar na escola pública de periferia urbana: o caso da escola municipal de ensino fundamental Ferreira Vianna, Pelotas, RS. 2012. 197 f. Dissertação (Mestrado) - Programa de Pós-Graduação em Arquitetura e Urbanismo, Universidade Federal de Pelotas, Pelotas, 2012.

SANOFF, H. School design. New York: John Willey and Sons, 1994.

SANOFF, H.. School Building Assessment Methods. Washington: National Clearinghouse for Educational Facilities, 2001. Disponível em:<http://www4.ncsu.edu/ sanoff/schooldesign/schoolassess.pdf >. Acesso em: jun. 2016.

TAVARES FILHO, A. C. Reflexões sobre a Noção de Tipo Morfológico e o Programa Arquitetônico: Os Casos das Escolas Municipais Estados Unidos e República Argentina. 2005. 200 f. Dissertação (Mestrado) - Programa de Pós-graduação em Arquitetura, Universidade Federal do Rio de Janeiro, Rio de Janeiro, 2005.

\section{${ }^{1}$ Gracielle Rodrigues da Fonseca Rech}

Arquitetura e Urbanismo. Mestrado em Projeto e Tecnologia do Ambiente Construído pela Universidade Federal de Santa Catarina. Endereço Postal: Rua Elíria Bonafé, 75, Palmitinho, RS, Brasil, 98430-000

\footnotetext{
2 Ângela do Valle

Engenharia Civil. Doutorado em Engenharia Civil pela Universidade de São Paulo, na área de concentração em estruturas.
} 
Professora Associada da Universidade Federal de Santa Catarina. Endereço Postal: Departamento de Engenharia Civil, UFSC, Rua João Pio Duarte Silva, 205, Córrego Grande, Florianópolis, SC, Brasil, 88037-000

\section{${ }^{3}$ Bruna Cristina Lermen}

Acadêmica de Arquitetura e Urbanismo, $9^{\circ}$ semestre. Endereço Postal: Linha Zachi, n50, Pinheirinho do Vale, RS, Brasil, 98435 000 